\title{
CONCEPT MODELING AND ANALYSIS OF BODY IN WHITE USING BEAM ELEMENTS
}

\author{
Praveen Padagannavar and Manohara Bheemanna \\ School of Aerospace, Mechanical \& Manufacturing Engineering \\ Royal Melbourne Institute of Technology (RMIT University) \\ Melbourne, VIC 3001, Australia
}

\begin{abstract}
In this paper, Concept Modeling and Analysis of Body in White by using Hpermesh software is discussed. The companies first design the concept model of the car by using a CAD software. Altair Hyperworks software is used to create models. Beam and shell elements have been used to design the Body-inwhite structure of the vehicle. The modeling has done by using beam elements for creating the structural frame of the car, the model is imported and solved using MD Nastran. In order to perform the modal analysis of the model SOL 103 is used. The mode shapes and natural resonance frequencies can be visualised using Hyperview software. The frequency response functions of Inphase, Outphase and Single node are detailed. The SOL 111 is used to obtain the Frequency response functions under different conditions. The graphs are visualised using Hypergraph software. Based on the structural integrity the design of structure, alterations are done to it to get satisfactory values which can make the car stiffer. The results obtained confirms to the actual model, which can be compared with any hatchback vehicle.
\end{abstract}

Key words: Beam Elements, Steel, Hypermesh Model, ModeshapesSOL103, FRF Graphs- SOL111, Cavity Modeling.

Cite this Article: Praveen Padagannavar and Manohara Bheemanna, Concept Modeling and Analysis of Body In white Using Beam Elements. International Journal of Design and Manufacturing Technology 7(1), 2016, pp. 23-36. https://iaeme.com/Home/issue/IJDMT?Volume=7\&Issue $=1$

\section{INTRODUCTION}

Concept Modeling is the abstraction of the vehicle model from the real model. The detailed Finite Element model may or may not exist when the concept model is designed. It implies the need for simplification of the real system and assumptions about unknown quantities. The concept model can be used to test future designs or make design changes to existing models. 
Modal analysis is the process of evaluating the natural frequencies, damping factors and mode shapes, in order to study the systems dynamic behavior. The natural modes of the vibration are completely determinant on the physical properties such as mass, stiffness and damping. The basis of testing is upon establishing the relation between the vibration response at one location and the excitation at the same or different location. This relationship is called as Frequency Response Function. In automotive engineering, modal analysis is an important role in studying vehicle noise and vibration harshness.

Companies usually make a concept model or a prototype before making the final product and with the help of software the particular model is analyzed and tested to check its stability. Earlier there was no software to test the prototype and to do the crash analysis. Often it was required lot of initial investment of money and time. In order to overcome with this problem, companies started using software \& as a result it saved a huge amount of money and time.

Altair Hyperworks is a design platform for optimization, performance data management and process automation. It provides integrated tools for modeling, analysis, optimization, visualization, and reporting performance data management. Hpermesh is a powerful tool for creating and understanding finite-element models and Hyperview is a general purpose visualization tool for viewing the output of CAE results. Hypergraph provides a data analyzing platform for plotting and testing data in various formats.

\section{METHODOLOGY OF MODELLING}

The method used in this model is beam modeling approach. The main structure is created as beam sections. Using beam model, the complex structures of the vehicle body becomes easier, which is usually preferred. For the roof, floor, and glass shell elements are used by providing specific course density. The automotive body has number of parts that influence the structural integrity of the vehicle. Due to the large number of parts, simulation software is developed which takes the dimensional data and generates required meshing order for the structure and this can be analyzed using hypergraph and hyperview.

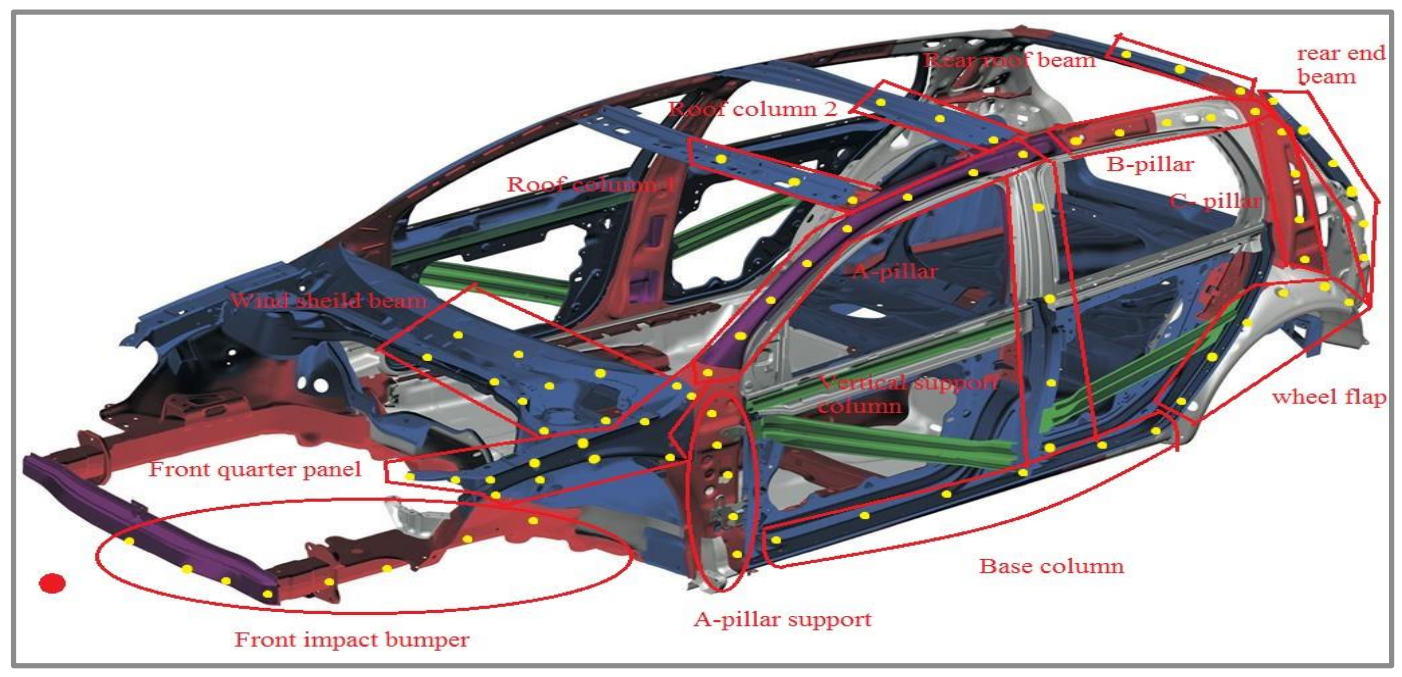

Figure 1 Body in White with names of individual parts as done in following modeling (Autoraan.com, 2012) 


\section{1: CREATING NODES AND CONNECTING LINES}

- Launch the Hypermesh software.

- Using "Geometry" options create the "Nodes" according to the required model and according to the dimensions. Draw all the nodes of one side as per the model requirement. This is important step because we need to concentrate on coordinates and ensure avoiding overlapping of nodes.

- On creating the nodes, the half model of the vehicle is created and then translated according to the dimensions.

- In order to translate nodes, select the required nodes and click on "Translate+".

- To reflect the nodes, select all the required nodes, duplicate and then reflect it.

- The nodes will be connected by lines to form the connections. The lines formed will represent the wireframe model of the car. Straight lines and smooth lines are used to connect the nodes.

\section{Nodes for BIW:}

\begin{tabular}{|c|c|c|c|c|}
\hline Component & $\mathbf{X}$ & $\mathbf{Y}$ & $\mathbf{Z}$ & Comments \\
\hline \multirow{8}{*}{ Front Quarter panel } & 420 & 100 & 720 & $\begin{array}{c}\text { Need translation } \\
\text { on Y axis }\end{array}$ \\
\hline & 450 & 70 & 720 & \\
\hline & 500 & \multirow{30}{*}{30} & 720 & \\
\hline & 600 & & 730 & \\
\hline & 800 & & 740 & \\
\hline & 1000 & & 745 & \\
\hline & 600 & & 600 & \\
\hline & 420 & & 600 & \\
\hline \multirow{5}{*}{$\mathrm{A}-$ pillar support } & 1240 & & 760 & \\
\hline & 1240 & & 700 & \\
\hline & 1300 & & 500 & \\
\hline & 1350 & & 250 & \\
\hline & 1400 & & 50 & \\
\hline \multirow{6}{*}{ Base column } & 1500 & & \multirow{6}{*}{50} & \\
\hline & 1800 & & & \\
\hline & 2000 & & & \\
\hline & 2300 & & & \\
\hline & 2500 & & & \\
\hline & 2990 & & & \\
\hline \multirow{6}{*}{ Wheel flap } & 3000 & & 100 & \multirow{6}{*}{$\begin{array}{l}\text { Adjust the node } \\
\text { height to get } \\
\text { curvature }\end{array}$} \\
\hline & 3200 & & 200 & \\
\hline & 3500 & & 290 & \\
\hline & 3800 & & 380 & \\
\hline & 4000 & & 290 & \\
\hline & 4150 & & 200 & \\
\hline \multirow{6}{*}{ A - Pillar } & 1300 & & 760 & \\
\hline & 1200 & & 800 & \\
\hline & 1250 & & 1000 & \\
\hline & 1400 & & 1050 & \\
\hline & 2000 & & 1250 & \\
\hline & 2175 & & 1310 & \\
\hline B- Pillar & 2300 & & 1300 & \\
\hline
\end{tabular}


Praveen Padagannavar and Manohara Bheemanna

\begin{tabular}{|c|c|c|c|c|}
\hline Component & $\mathbf{X}$ & $\mathbf{Y}$ & $\mathbf{Z}$ & Comments \\
\hline & 2400 & & 1300 & \\
\hline & 2700 & & 1290 & \\
\hline & 3100 & & 1280 & \\
\hline & 3430 & & 1270 & \\
\hline \multirow{4}{*}{ C- pillar } & 3430 & & 1270 & \\
\hline & 3470 & & 900 & \\
\hline & 3500 & & 600 & \\
\hline & 3500 & & 360 & \\
\hline \multirow{6}{*}{ Rear End beams } & 3600 & & 1270 & \\
\hline & 3800 & & 1100 & \\
\hline & 4000 & & 960 & \\
\hline & 4150 & & 860 & \\
\hline & 4150 & & 760 & \\
\hline & 4150 & & 660 & \\
\hline \multirow{4}{*}{$\begin{array}{l}\text { Vertical Support } \\
\text { beam }\end{array}$} & \multirow{4}{*}{2175} & 30 & 1200 & \\
\hline & & 20 & 1000 & \\
\hline & & 20 & 500 & \\
\hline & & 30 & 100 & \\
\hline \multirow{6}{*}{ Wind shield beam } & 1240 & 100 & 760 & \\
\hline & 1180 & 500 & \multirow{3}{*}{760} & \\
\hline & 1120 & 900 & & \\
\hline & 1120 & 500 & & \\
\hline & 700 & 30 & 740 & \\
\hline & 900 & 50 & 720 & \\
\hline \multirow{3}{*}{ Roof column 1} & \multirow{3}{*}{1600} & 100 & \multirow{3}{*}{1100} & \\
\hline & & 500 & & \\
\hline & & 900 & & \\
\hline \multirow{3}{*}{ Roof column 2} & \multirow{3}{*}{2175} & 100 & \multirow{3}{*}{1310} & \\
\hline & & 500 & & \\
\hline & & 900 & & \\
\hline \multirow{3}{*}{ Rear roof beam } & \multirow{3}{*}{3430} & 100 & \multirow{3}{*}{1270} & \\
\hline & & 500 & & \\
\hline & & 900 & & \\
\hline \multirow{7}{*}{$\begin{array}{c}\text { Front impact } \\
\text { bumper }\end{array}$} & 0 & 900 & \multirow{7}{*}{250} & \\
\hline & 100 & 750 & & \\
\hline & 200 & 500 & & \\
\hline & 250 & \multirow{4}{*}{250} & & \\
\hline & 500 & & & \\
\hline & 800 & & & \\
\hline & 1300 & & & \\
\hline
\end{tabular}

Table No 1. Nodes 

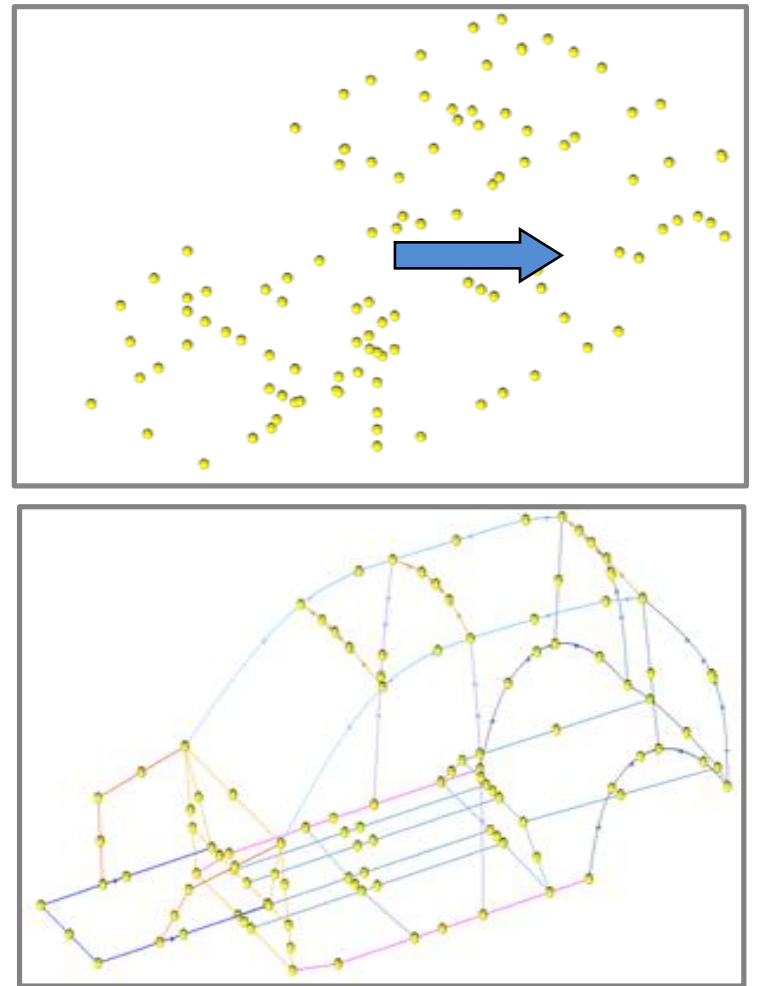

Figure 2 Nodes and Connecting lines

\subsection{CREATING THE CROSS-SECTIONS OF THE BEAMS}

- To create 1D beam elements use hyperbeam with thin walled standard cross section.

- Specify the height (a), width (b) and thickness ( $t$ ) of the element.

- Make the cross-section according to the model and assign the dimension accordingly.

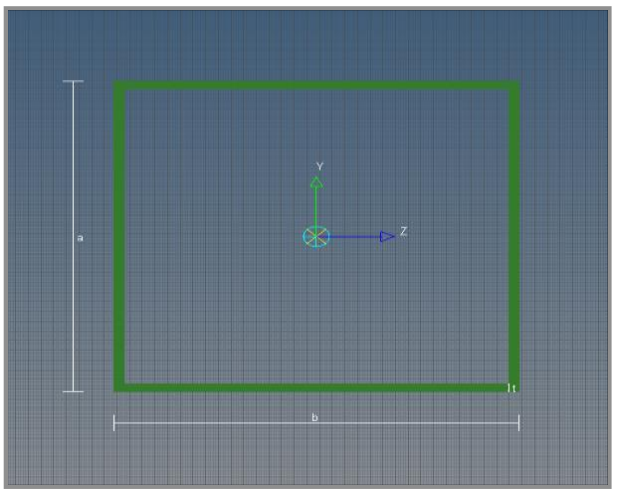

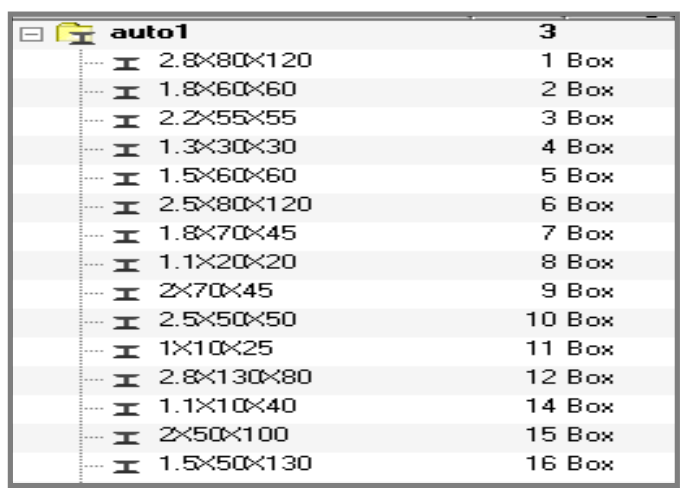

Figure No 3. Steps of cross section

\subsection{CHOOSE MATERIAL FOR THE MODEL}

- The material used for building the frame of the vehicle is assumed as Steel. The material type created will be isotropic and card image will be MAT1.

- The properties of the steel material are created and edited by inserting the values as shown below table. 


\begin{tabular}{|c|c|}
\hline & STEEL \\
\hline Young's modulus, $\mathrm{E}$ & $2.1 \mathrm{e}+08$ \\
\hline Poissons ratio, Nu & $\mathbf{0 . 3}$ \\
\hline Density, RhO & $\mathbf{7 . 8 e - 6}$ \\
\hline GE & 0.01 \\
\hline
\end{tabular}

Table No 2 Material property selected for the model

\subsection{CREATING PROPERTIES}

- The properties of the component are created by assigning the material, type of the element, colour, card image, and cross section for the required body part.

- The element type of beam members '1D' and card image is 'PBEAM'.

- For cavity use 'AIR' as the element and use 3D FLUID.

- For shell members use the element type as '2D' and card image as 'PSHELL'.

\subsection{CREATING COMPONENTS}

- Create the components which are required for the modelling. Likewise front impact bumper, A-pillar, B-pillar, Floor panel, Front quarter panel, Rear beam and wheel flap.

- After creating the components, each property is assigned to a component of individual parts.

- The card image is assigned from the property that is selected from the list.

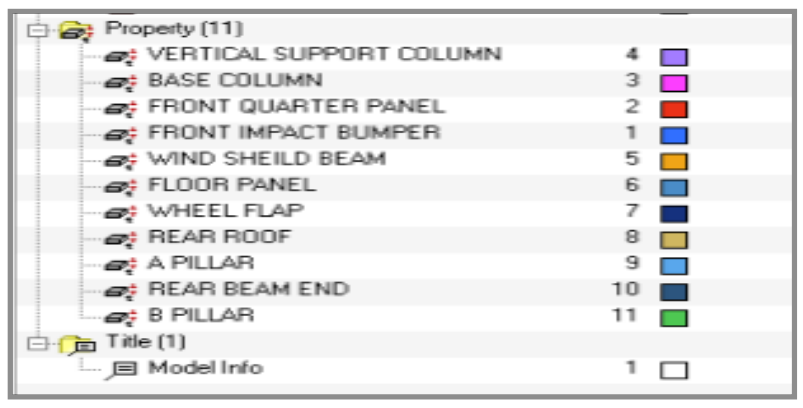

Figure No 4 List of the properties for this model

\subsection{CREATING MESH}

- Using line mesh, lines are meshed by assigning the corresponding hyperbeams. The element configuration selected is bar2, because it helps in determining bending or torsional movements between any two nodes.

- All parallel lines are meshed in auto mesh mode. All vertical lines, inclined lines and smooth lines are meshed by vector mesh with $\mathrm{x}$-axis as the reference. This is because the system cannot identify the direction by itself.

- Meshing the model will divide the components into small elements which optimizes the model results. 


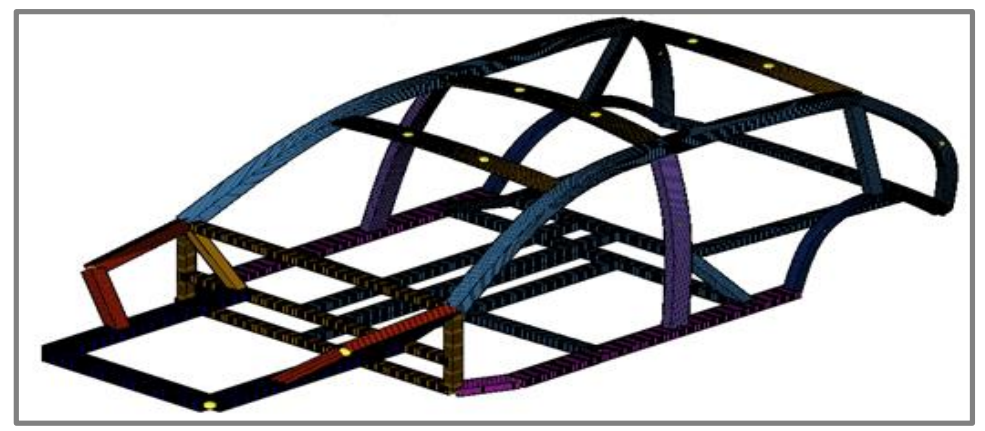

Figure No 5 Model after meshing

\subsection{CHECK THE EDGES, FREE ELEMENTS, NODES AND MASS}

- Check for the free elements by using the preview equivalence. This is done to connect all the meshed components at the mating points of different components. This will ensure that all the elements are connected to form a single model.

- If there are any free ends, increase the tolerance at the mating points and do the preview equivalence again to ensure there are no free $1 \mathrm{~d}$ elements left. After equivalence, the number of nodes in equivalence will be displayed.

- Select all the elements and check for the mass of the model by using "mass calc". This will display the mass of the model.

NOTE: For hatchback car, the structure weight should be around 200 to $250 \mathrm{~kg}$. For this model the weight was found to be $211 \mathrm{~kg}$ and the numbers of elements are 4743 .

\subsection{EXPORT THE MODEL, SOLVE IN NASTRAN AND VIEW MODE SHAPES IN HYPERVIEW (SOL 103)}

- The model is then exported in .bdf format to solve in MD NASTRAN. The exported file is edited by removing the CEND, BEGIN BULK and END DATA from the file. The file name is then attached to the SOL103 JCL file before solving.

- The JCL file is then run in MD NASTRAN to obtain the jcl.op2 file. This file consists of the results, which is imported to the Hyperview window to view the mode shapes and the frequencies.

\subsection{VIEW FREQUENCY RESPONSE FUNCTION GRAPH IN HYPERGRAPH (SOL 111)}

- Frequency response function is a measure of magnitude and phase of the output as a function of frequency, in comparison to the input. The magnitude is measured in decibels and the frequency is measured in Hertz.

- The input nodes which are usually the areas of engine mounts and suspension should be defined in JCL file, which has a code line DAREA entry. The DAREA line defines the degrees of freedom for the applied dynamic load and applied scale factor of loading.

- The input and output nodes for FRF are chosen.

- For the solution sequence SOL 111, multiple sub cases may be selected.

- On solving, a Compiled resource script file is obtained. 
- The .res file is imported in Hypergraph to plot the graph of acceleration of all the output nodes in Mag $\mathrm{Z}$ direction.

\section{RESULTS OF THE MODEL}

\subsection{MODE SHAPES OF THE MODEL -- SOL 103}

\section{SOL 103: It is a solution sequence used to execute normal modal analysis} and natural frequency calculation.

The SOL 103 statement is used in the JCL file for the analysis of the mode frequencies of car structure. In JCL file the EIGRL value is defined as 200 to attain a larger frequency range. The EIGRL entry defines the method and selects the parameters that control the Eigen values which are the number of modes.

The first six modes are not considered as the values are below zero and they are rigid modes. Which means no movement of the car body can be observed. From mode 7 to mode 12, proper mode shapes are observed which consists of bending and torsion.
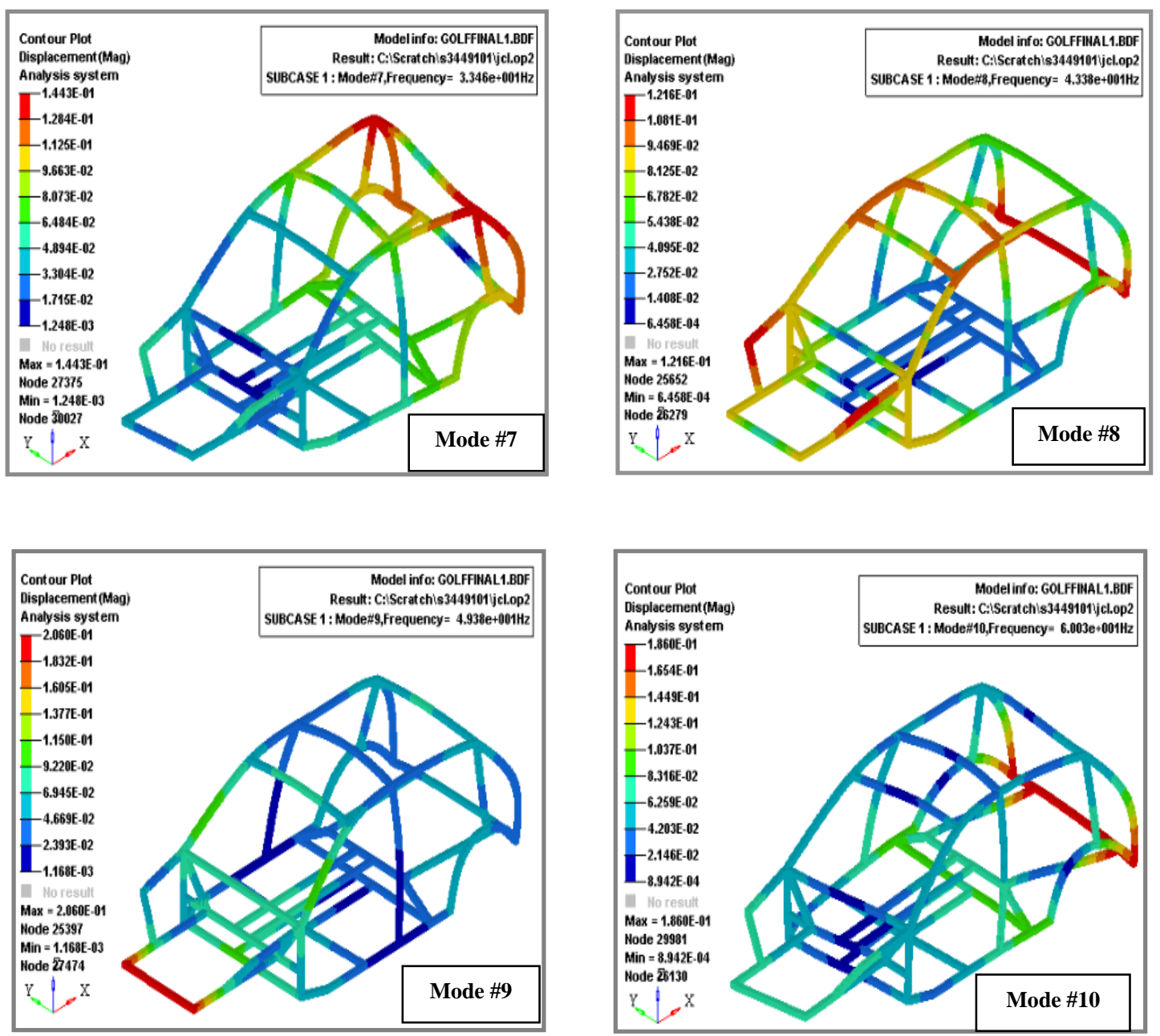

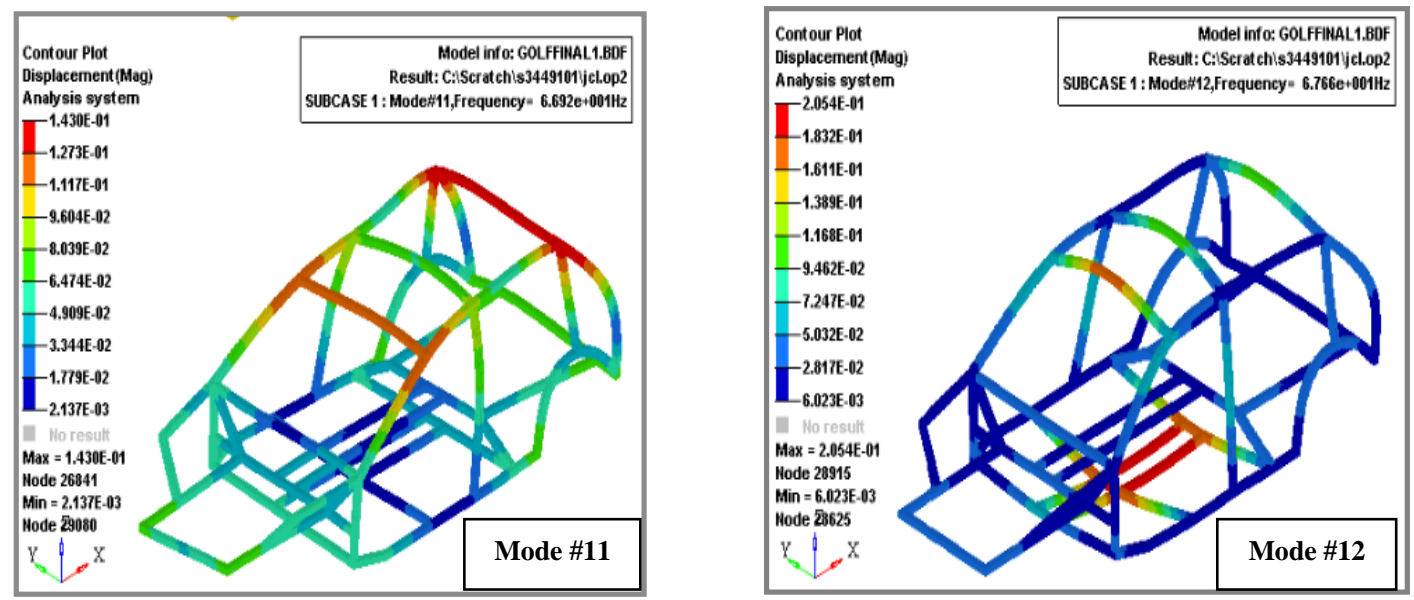

Figure No 6 Mode shapes

\subsection{RESULTS OF FREQUENCY RESPONSE FUNCTION OF THE MODEL-- SOL 111}

SOL 111: It is a solution sequence used to solve modal frequency response problems like vehicle noise, rocket launch and earthquake analysis.

SOL111 is used to obtain the frequency response function and the analysis of Inphase, Out-phase and Single node frequencies of selected nodes on structure of the car. Its main purpose is to confirm with the resonant frequencies obtained using SOL103 are bending, torsional or lateral. The input nodes are on front impact bumper and output nodes are on base column. In this model the nodes used to obtain the Frequency Response Function is shown in the below figures.

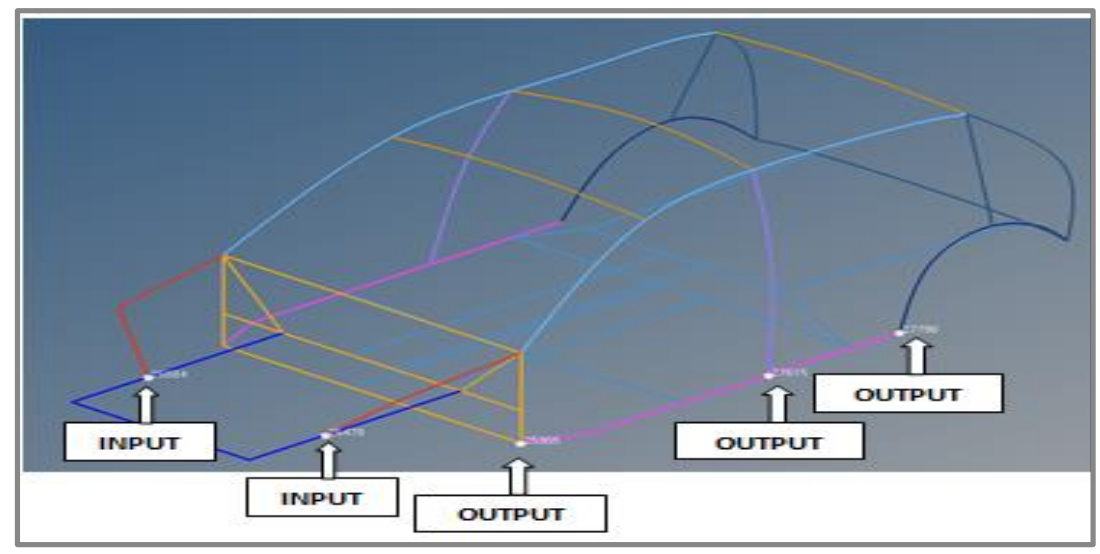

Figure No 7. Input and Output nodes

Single-node Excitation: The peaks of the graph show the excitation at the output nodes. The peaks are the resultant of torsion \& bending moments that have reflected from the model. The peak of the graphs shows both the bending and torsional moment at the output nodes in the form of Frequency Response Function. 


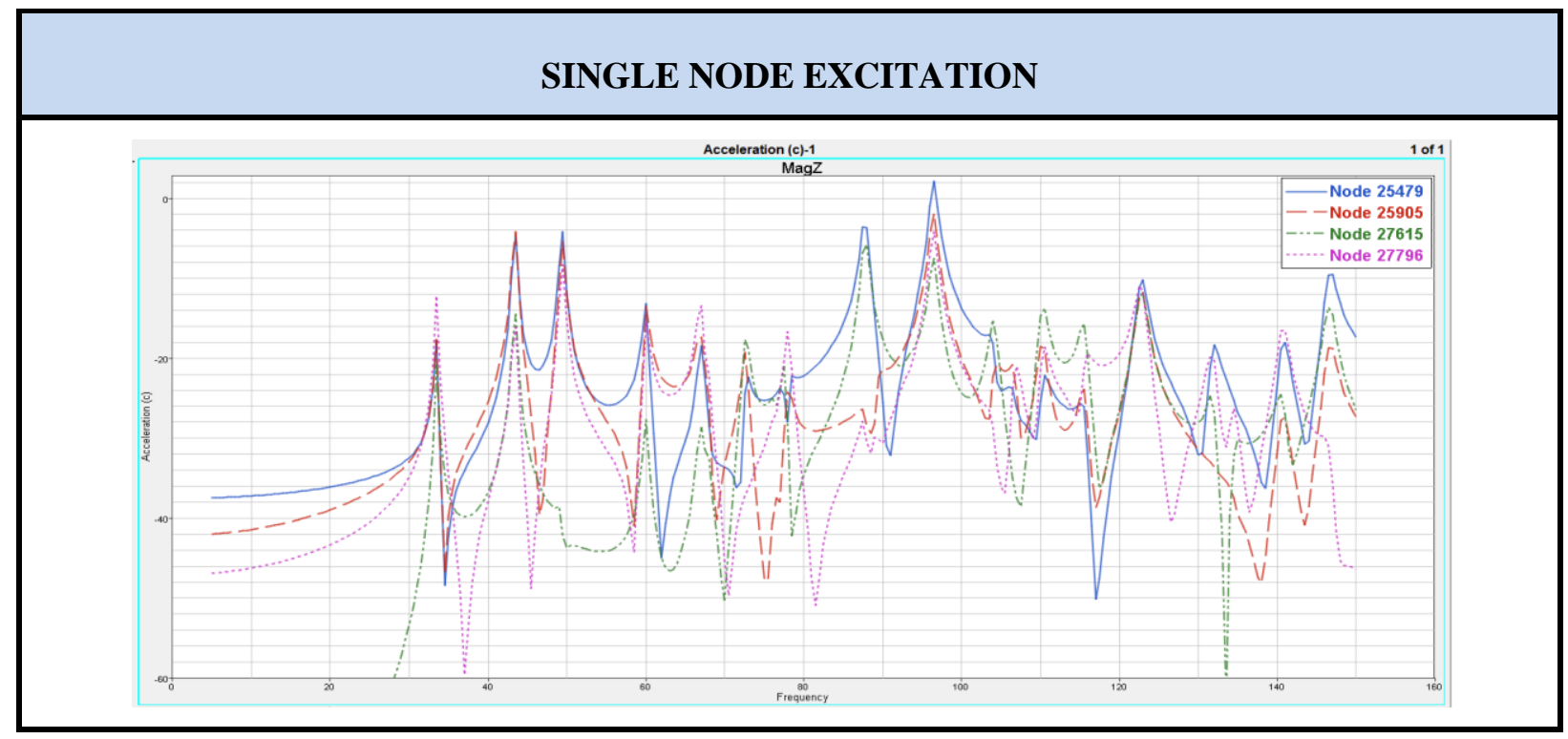

Figure No 8. Single node FRF graph (linear and db 20)

NOTE: For single node, the input node is 25584 and the output nodes are 25479, 25905, 27615, and 27796.

In-phase Excitation: In order to obtain the results for bending resonant frequencies we need to do in-phase excitation and for this both input nodes are given in same direction. The peak of the graphs shows the bending moment at the output nodes in the form of Frequency Response Function.

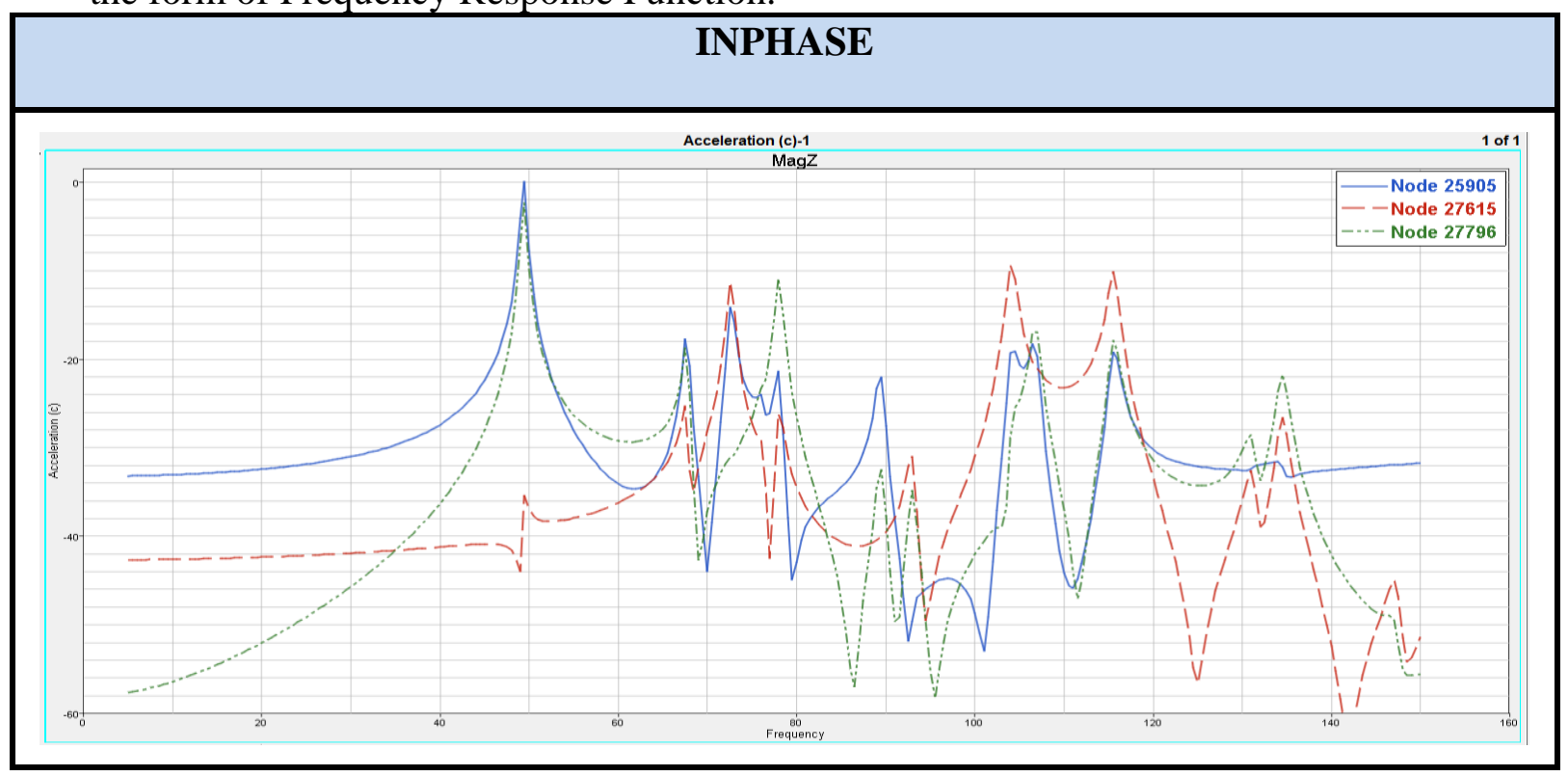

Figure No 9. In-phase FRF graph (linear and db20)

NOTE: For in phase, the input node is 25584 and 25479 and the output nodes are 25905, 27615, 27796.

Out-phase Excitation: The Frequency Response Function (FRF) for the torsion moment is obtained by making the excitation on the input nodes in opposite directions. The peak of the graphs shows the torsional bending moment at the output nodes in the form of Frequency Response Function. 


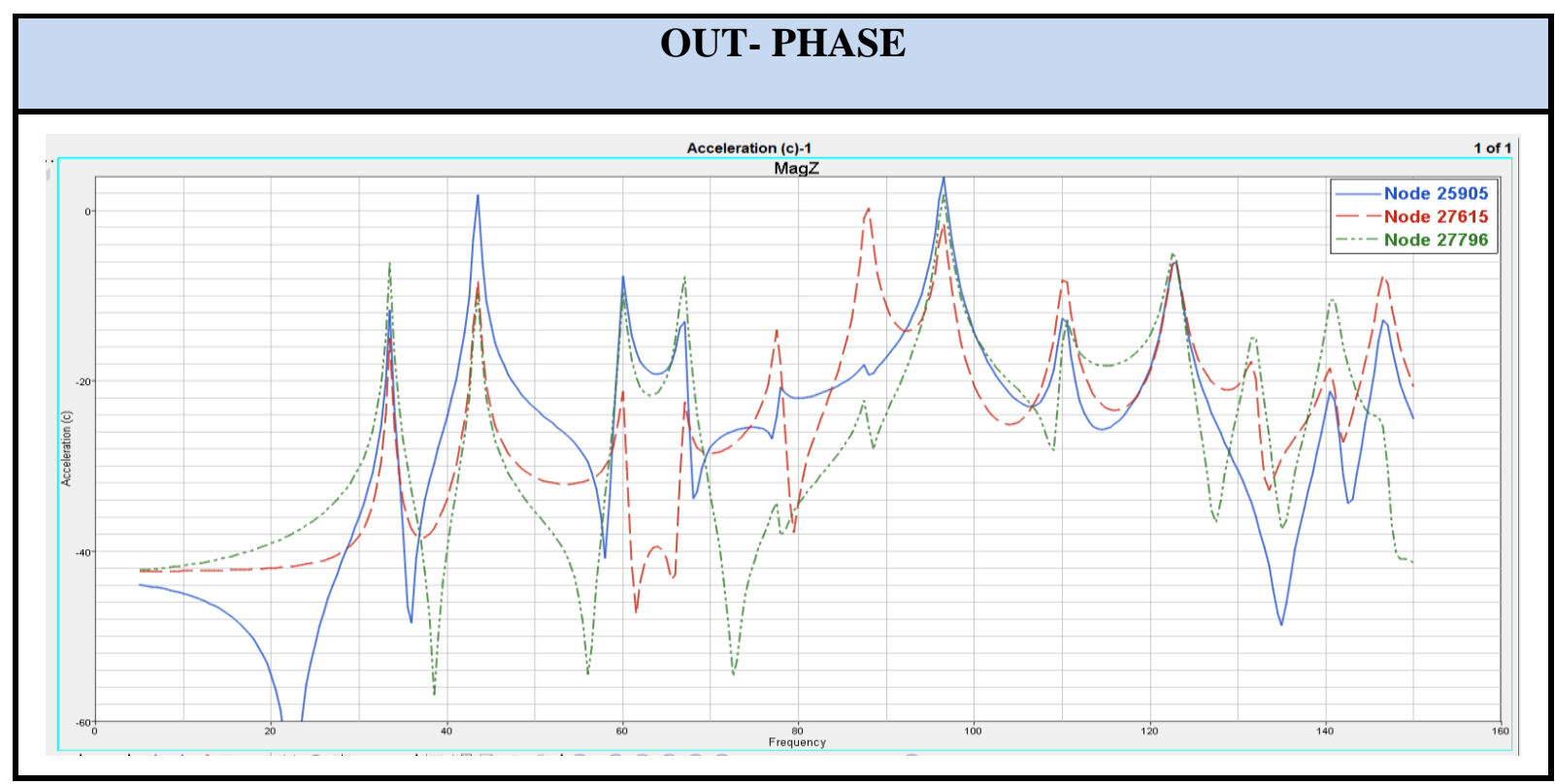

Figure No 10. Out phase FRF graph (linear and db 20)

NOTE: For out-phase, the input node is 25584 and 25479 and the output nodes are 25905, 27615, and 27796.

\subsection{DISCUSSION OF THE RESULTS}

\begin{tabular}{|c|c|c|c|c|}
\hline & $\begin{array}{c}\text { RESONANT } \\
\text { FREQUENCY } \\
(\mathbf{H z})\end{array}$ & $\begin{array}{c}\text { MAX- } \\
\text { DISPLACEMENT }\end{array}$ & $\begin{array}{c}\text { MIN- } \\
\text { DISPLACEMENT }\end{array}$ & MODE SHAPES \\
\hline MODE 7 & $33.46 \mathrm{HZ}$ & $1.443 \mathrm{E}-01$ & $1.248 \mathrm{E}-03$ & TORSION \\
\hline MODE 8 & $43.38 \mathrm{HZ}$ & $1.216 \mathrm{E}-01$ & $6.458 \mathrm{E}-04$ & VERTICAL BENDING \\
\hline MODE 9 & $49.38 \mathrm{HZ}$ & $2.060 \mathrm{E}-01$ & $1.168 \mathrm{E}-03$ & LATERAL BENDING \\
\hline MODE 10 & $60.03 \mathrm{HZ}$ & $1.860 \mathrm{E}-01$ & $8.942 \mathrm{E}-04$ & $\begin{array}{c}\text { SECOND LATERAL } \\
\text { BENDING }\end{array}$ \\
\hline MODE 11 & $66.92 \mathrm{HZ}$ & $1.430 \mathrm{E}-01$ & $2.137 \mathrm{E}-03$ & SECOND BENDING \\
\hline MODE 12 & $67.66 \mathrm{HZ}$ & $2.054 \mathrm{E}-01$ & $6.023 \mathrm{E}-01$ & TORSION \\
\hline
\end{tabular}

Table No 3 Mode shapes and resonant frequencies

- SOL 111 is used to analyze forced vibrations. It is used to plot the frequency response function so that the mode shapes of the structure obtained from SOL 103 can be confirmed.

- On plotting the graphs, we obtain a vertical graph which is ratio of Acceleration to input in $\mathrm{dB}$ by the frequency in $\mathrm{Hz}$.

- When the inputs are In-phase, the peaks in Frequency Response Function confirm the Bending resonant frequencies.

- When the inputs are Out of phase, the peaks in Frequency Response Function confirm the Torsion resonant frequencies. 
- When the input is at a single node, the peaks in Frequency Response Function have both bending and torsion resonant frequencies.

- When the input and output are at the same node, Inertance is noticed.

\section{CAVITY MODELLING}

The main aim of the cavity modeling is to analyze the resonant frequencies of the interior cavity and make adjustments to the panels so that cabin noise can be minimum or reduced.

\section{Steps for creating cavity model:}

- Nodes are selected for the car cavity.

- Create material and property card.

- Create solid mesh and update the component to ensure that the property is assigned properly.

- Ensure all the fluid grid points are CD-1 and export the model.

- To determine the fluid elements, we need to select the MAT10 property and specify the Bulk modulus and speed of sound.

- Nastran can be used to perform a fully coupled fluid-structure analysis. The interface between the fluid and structure can be modeled such that the grid points of fluid and structure are coincident.

- Finally, run the JCI file in the Nastran software and open the '.op2' file in hyperview to visualize the modes.

\section{The equation for cavity resonant is:}

\section{F=Sound speed/(interior length*2)}

\section{$\mathbf{f}=340 /($ interior length $* 2)$}

where,

speed of sound $=340 \mathrm{~m} / \mathrm{s}$

interior length $=2.5 \mathrm{~m}$

\subsection{RESULTS OF CAVITY MODELING}

The cavity represents the interior model of the vehicle. Using Nastran Solvent (SOL103) various resonance frequencies and its mode shapes of the given model is determined. The mode shapes represents the pressure difference that the cavity experiences for different frequencies. Air is used as Fluid in the cavity, it becomes necessary to increase the deformation points to higher values so that modes shape at various resonance frequencies are determined. The cavity model is simulated and observed as shown below. 

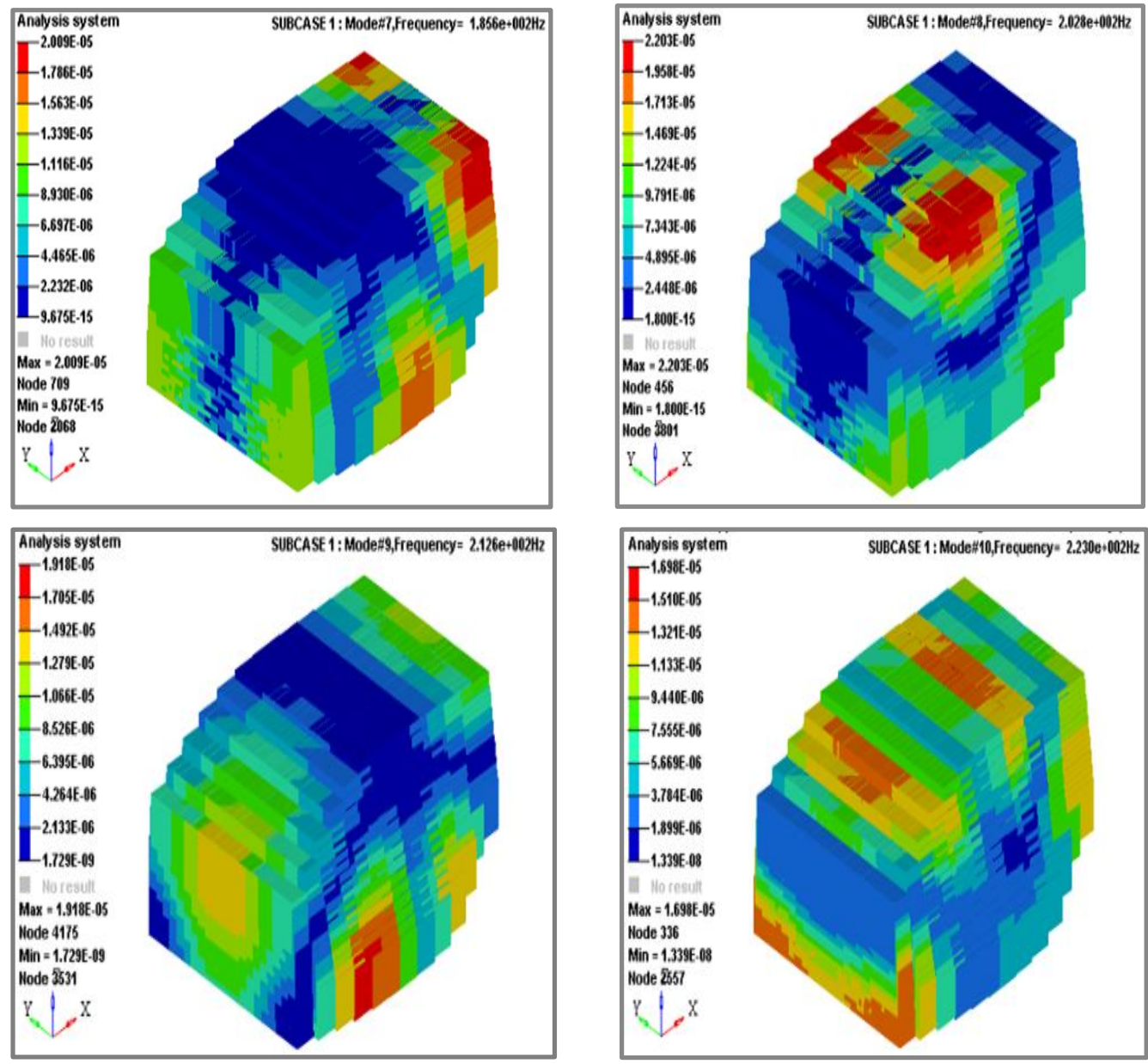

Figure No 11 Cavity mode shapes

\section{CONCLUSION}

The concept model for a Hatchback has been designed and analyzed. The result satisfies the actual model requirements and also it gives good effectiveness real model. All the modes shape and the FRF graphs are accurate. Hence by opting for concept modeling, a lot of modeling time, money, analysis time and space can be saved. It could be used to predict results at the early design stages and modify flaws in the existing design. It is very helpful in performing $\mathrm{NVH}$ analysis in order to reduce vehicle noise. Thus concept modeling is one of the best methods in automotive industry which provides accurate results in less time as compared with that of actual modeling.

\section{The advantages of concept modeling are:}

1. Useful in analyzing the structural dynamics of the vehicle.

2. Saves lot of time compared to the detailed finite element model.

3. It requires very small space compared to a detailed Finite Element model.

4. Design changes can be suggested at the early stages, so that time and money can be saved. 


\section{REFERENCES}

[1] Robinson (2010), Conceptual modeling [online]. Available at: http://www.scs.org/magazines/2010-04/index_file/Files/Robinson.pdf.

[2] http://en.wikipedia.org/wiki/Bending

[3] Dr.Thota, J., n.d. Lecture 5: Altair: Material Model and Units.

[4] Robinson, S., 2010. Conceptual Modelling: Who Needs It?. SCS M\&S Magazine.

[5] Cartype.com, (2015). Car Line Art | Car type. [online] Available at: http://cartype.com/pages/4507/car_line_art [Accessed 21 Oct. 2015].

[6] Bhavik M.Patel, Ashish J. Modi and Prof. (Dr.) Pravin P. Rathod, Analysis of Engine Cooling Waterpump of Car \& Significance of Its Geometry. International Journal of Design and Manufacturing Technology 4(3), 2014, pp. 100-107.

[7] Autoraan.com, (2012). The new Volkswagen Golf-Das Auto" is now VW Golf 7 AUTOraan.com. [online] Available at: http://www.autoraan.com/the-new-volkswagen-golf-das-auto-is-now-vwgolf-7/ [Accessed 21 Oct. 2015]. 